\title{
Pemberdayaan Ibu Rumah Tangga Melalui Kewirausahaan Sabun Piring Cair
}

\author{
${ }^{1}$ Menik Aryani, ${ }^{2}$ Ratna Azizah Mashami, ${ }^{2}$ Ahmadi, ${ }^{3}$ Dewi Rayani, ${ }^{3}$ Jessica Festy \\ Maharani \\ 1,2,\& ${ }^{3}$ Universitas Pendidikan Mandalika. Pemuda No. 59A, Mataram, Indonesia 83125
}

Email Korespondensi: ratnamashami@ikipmataram.ac.id

\begin{tabular}{|c|c|}
\hline Article Info & Abstract \\
\hline $\begin{array}{l}\text { Article History } \\
\text { Received: } \\
\text { Revised: } \\
\text { Published: }\end{array}$ & \multirow{2}{*}{$\begin{array}{l}\text { Empowerment of Housewives Through Liquid Dish Soap Entrepreneurship. } \\
\text { The large number of housewives (IRT) can be a potential human resource in } \\
\text { developing the family and regional economy. But most IRTs do not have the } \\
\text { skills to entrepreneurship. Therefore, the team made efforts to empower IRT } \\
\text { through liquid soap dish entrepreneurship. The purpose of this activity is } \\
\text { twofold, namely providing knowledge and skills to make liquid dish soap to the } \\
\text { IRT and increasing IRT's interest in entrepreneurship. This activity was carried } \\
\text { out in Gondang Village, North Lombok Regency and attended by } 24 \text { IRT } \\
\text { people. The method of implementation uses. PRA (Participatory Rural } \\
\text { Appraisal) method with stages of counseling, training, and mentoring. The } \\
\text { success rate of this activity is measured based on IRT responses and the results } \\
\text { of product sales. For one month the empowerment of the IRT in Gondang } \\
\text { Village was successfully carried out. The IRT has gained knowledge and skills } \\
\text { in making liquid dish soap. In addition, IRTs are increasingly motivated to } \\
\text { become entrepreneurs through liquid dish soap. Enthusiastic participants were } \\
\text { seen from the beginning to the end of the activity. In addition, the sale of liquid } \\
\text { dish soap has been seen to increase IRT revenue. }\end{array}$} \\
\hline $\begin{array}{l}\text { Keywords } \\
\text { housewife; } \\
\text { entrepreneurship; } \\
\text { liquid soap dish }\end{array}$ & \\
\hline Inform & Abstrak \\
\hline $\begin{array}{l}\text { Sejarah Artikel } \\
\text { Diterima: } \\
\text { Direvisi: } \\
\text { Dipublikasi: }\end{array}$ & \multirow{2}{*}{$\begin{array}{l}\text { Jumlah Ibu Rumah Tangga (IRT) yang banyak bisa menjadi sumber daya } \\
\text { manusia yang potensial dalam membangun perekonomian keluarga dan daerah. } \\
\text { Tetapi sebagian besar IRT tidak memiliki keterampilan untuk berwirausaha. } \\
\text { Oleh karena itu, tim melakukan upaya pemberdayaan IRT melalui } \\
\text { kewirausahaan sabun piring cair. Tujuan kegiatan ini ada dua, yakni } \\
\text { memberikan pengetahuan dan keterampilan membuat sabun piring cair kepada } \\
\text { IRT serta meningkatkan minat IRT untuk berwirausaha. Kegiatan ini } \\
\text { dilaksanakan di Desa Gondang Kabupaten Lombok Utara dan diikuti oleh } 24 \\
\text { orang IRT. Metode pelaksanaan menggunakan. Metode PRA (Participatori } \\
\text { Rural Appraisal) dengan tahapan penyuluhan, pelatihan, dan pendampingan. } \\
\text { Tingkat keberhasilan kegiatan ini diukur berdasarkan respon IRT dan hasil } \\
\text { penjualan produk. Selama satu bulan pemberdayaan IRT di Desa Gondang } \\
\text { telah berhasil dilaksanakan. Para IRT telah mendapatkan pengetahuan dan } \\
\text { keterampilan dalam membuat sabun cair piring. Selain itu, IRT semakin } \\
\text { termotivasi untuk berwirausaha sabun piring cair. Antusias peserta terlihat dari } \\
\text { awal sampai akhir kegiatan. Selain itu, penjualan sabun piring cair sudah } \\
\text { terlihat dapat meningkatkan pendapatan IRT. }\end{array}$} \\
\hline $\begin{array}{l}\text { Kata kunci } \\
\text { ibu rumah } \\
\text { kewirausahaan; } \\
\text { sabun piring cair }\end{array}$ & \\
\hline
\end{tabular}

Sitasi: Aryani M., Mashami A.R., Ahmadi., Rayani D., \& Maharani F.J. (2020) Pemberdayaan Ibu Rumah Tangga Melalui Kewirausahaan Sabun Piring Cair. Sasambo: Jurnal Abdimas (Journal of Community Service). 2(2), 80-85 DOI : 10.36312/sasambo.v2i2.219 


\section{PENDAHULUAN}

Kewirausahaan adalah usaha untuk menciptakan nilai tambah dengan jalan mengkombinasikan semua sumber daya ekonomi melalui cara-cara baru dan berbeda untuk memenangkan persaingan (Suharyono, 2017). Kewirausaha merupakan salah satu cara yang mudah untuk menambah pendapatan keluarga. Mudah karena tidak diperlukan banyak syarat untuk memulainya. Jika ada produk atau jasa yang dinilai bisa mendatangkan pendapatan maka usaha bisa langsung dimulai. Kewirausahaan juga tidak membutuhkan modal yang sangat besar dan bisa dimulai dari rumah. Salah satu manfaat kewirausahaan adalah meningkatkan kesejahteraan keluarga (Latifa, Dewi, \& Fitriana, 2018).

Wirausaha harus pintar dalam mengelola usahanya agar usaha yang dijalankan memiliki prospek yang bagus dan dapat bertahan lama. Hasil penelitian menunjukkan perkembangan usaha dipengaruhi oleh kompetensi wirausaha, pembinaan usaha, dan inovasi produk (Christiana, Pradhanawati, \& Hidayat, 2014). Wirausaha harus memikirkan produk inovatif yang dapat diandalkan karena persaiangan usaha saat ini semakin ketat. Produk merupakan ujung tombak dari suatu usaha terutama usaha kecil (Lang, Massie, \& Ogi, 2015). Produk yang dapat menghasilkan keuntungan yang besar adalah produk yang diminati banyak orang. Produk yang memiliki tingkat permintaan tinggi adalah produk yang dikonsumsi setiap hari dan dikonsumsi oleh setiap orang atau rumah tangga.

Produk pembersih merupakan kebutuhan pokok dalam rumah tangga, termasuk sabun pencuci piring. Aktivitas memasak dan makan setiap hari membuat banyak perabot dapur yang kotor sehingga membutuhkan sabun cuci. Sabun pencuci piring memiliki sejarah tersendiri. Dulu sabun pencuci piring berbentuk krim atau dikenal dengan istilah sabun colek. Saat ini sabun pencuci piring berbentuk cair lebih diminati oleh masyarakat. Tingkat permintaan masyarakat terhadap sabun piring berbentuk cair sangat tinggi. Hal ini dapat menjadi sebuah peluang usaha yang sangat menjanjikan karena target pemasaran terbuka lebar. Dari segi pembuatannya juga sangat mudah. Usaha ini tidak membutuhkan tenaga yang besar sehingga bisa dilakukan oleh seorang Ibu Rumah Tangga (IRT).

Berdasarkan data Badan Pusat Statistik Kabupaten Lombok Utara (BPS KLU) (2020), terdapat 22,57\% rumah tangga dari jumlah penduduk di Desa Gondang. Dengan demikian terdapar sekitar 2.500 orang yang berstatus sebagai IRT. Jumlah ini termasuk ke dalam penduduk usia kerja produktif yang didominasi oleh perempuan. Sebagian besar IRT tersebut adalah para istri yang tidak memiliki pekerjaan di luar rumah. Pendapatan keluarga mereka tergantung pada pekerjaan suami. Para IRT bukannya tidak ingin bekerja, tetapi mereka tidak memiliki kualifikasi untuk bekerja kantoran atau keterampilan untuk membuka kewirausahaan.

Perkembangan dunia usaha saat ini membutuhkan sumber daya manusia yang mandiri, kreatif dan inovatif untuk menghadapi persaingan (Rahim \& Basir, 2019). Jumlah IRT yang banyak bisa menjadi sumber daya manusia yang potensial dalam membangun perekonomian keluarga dan daerah. Pada tahun 2019, terdapat penduduk miskin sebesar 29,03\% di Kabupaten Lombok Utara (BPS KLU, 2020). Apabila IRT memiliki keterampilan membuat sabun piring cair maka mereka memiliki modal dasar untuk memulai kewirausahaan. Kewirausahaan diharapkan dapat mengurangi persentase penduduk miskin tersebut. Selain itu, dewasa ini IRT mempunyai peran ganda, bukan hanya mengurus aktivitas domestik tetapi juga ikut serta dalam mencari nafkah untuk memenuhi kebutuhan rumah tangganya (Telaumbanua \& Nugraheni, 2018).

Berdasarkan uraian di atas, tim melakukan upaya pemberdayaan IRT melalui kewirausahaan sabun piring cair. Adapun tujuan kegiatan ini ada dua, yaitu: (1) Memberikan pengetahuan dan keterampilan membuat sabun piring cair kepada IRT, dan (2) meningkatkan minat IRT untuk berwirausaha. 


\section{METODE PELAKSANAAN}

Kegiatan pengabdian kepada masyarakat dilaksanakan di Desa Gondang Kabupaten Lombok Utara. Dilaksanakaan dengan menggunakan Metode PRA (Participatori Rural Appraisal) dimana dalam pelaksanaannya melibatkan masyarakat setempat dalam seluruh kegiatan dan stakeholder (Wahyudi \& Septaryanto, 2020). Sasaran kegiatan adalah Ibu Rumah Tangga (IRT) sebanyak 24 orang. Kegiatan ini dilaksanakan selama satu bulan. Dengan tahapan-tahapan

1. Penyuluhan, kegiatan ini bertujuan untuk memberikan pemahaman dan pengetahuan kepada peserta tentang 1) kewirausahaan, 2) teknik pembuatan sabun piring cair, 3) pengemasan dan pemasaran.

2. Pelatihan pembuatan sabun piring cair.

3. Pendampingan, seluruh proses produksi sampai penjualan dilakukan oleh IRT dibawah pengawasan tim. Tingkat keberhasilan kegiatan ini diukur berdasarkan respon IRT dan hasil penjualan produk.

\section{HASIL DAN PEMBAHASAN}

Sebelum kegiatan dilaksanakan, tim telah berkoordinasi dengan Kepala Desa Gondang selaku pemerintah setempat. Kepala desa sangat mendukung kegiatan ini serta turut membantu persiapan kegiatan agar berjalan lancar. Peserta kegiatan ini adalah Ibu Rumah Tangga (IRT) yang ditunjuk oleh Kepala Desa berdasarkan tingkat ekonomi dan keinginan untuk membuka suatu usaha.

\section{Penyuluhan}

Kegiatan diawali dengan penyuluhan dengan tujuan mengedukasi IRT tentang kewirausahaan. IRT perlu menyadari alasan mereka membutuhkan sebuah usaha mandiri agar dapat menjadi pengingat dan penyemangat. Selanjutnya IRT diberikan materi langkahlangkah praktis yang perlu dilakukan untuk memulai kewirausahaan. Mereka diminta untuk menganalisis jenis usaha yang ada di sekitar mereka, penyebab usaha yang masih bertahan dan tidak, serta menilai peluang sebuah usaha. Kemudian, tim juga mengedukasi peserta tentang tips berjualan dan menaikkan omset. Penyuluhan ini berlangsung dengan lancar dan diikuti dengan serius oleh IRT. Hal tersebut terlihat dari peserta yang mengikuti penyuluhan dari awal sampai selesai dan peserta terlibat diskusi yang aktif dengan tim. Pelaksanaan penyuluhan seperti pada Gambar 1.
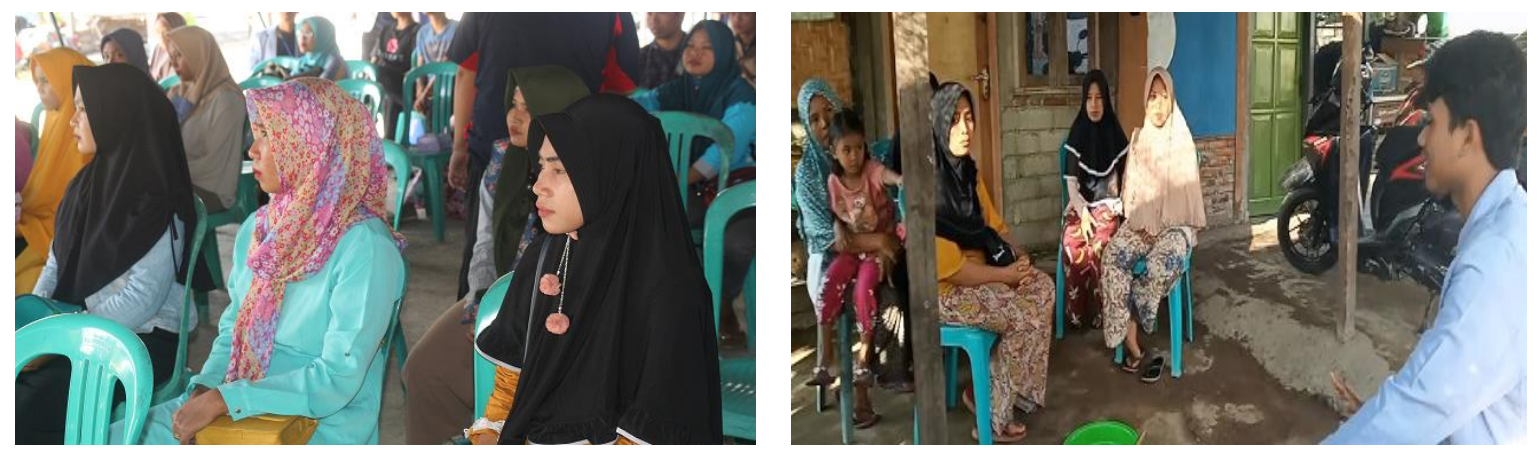

Gambar 1. Penyuluhan Kewirausahaan kepada Ibu Rumah Tangga

\section{Pelatihan}

Tahap selanjutnya dari kegiatan pemberdayaan IRT adalah pelatihan. Pelatihan diikuti oleh semua peserta yang mengikuti penyuluhan sebelumnya. Hal ini menunjukkan IRT Desa Gondang tertarik untuk membuka usaha sabun piring. Pelatihan pembuatan sabun cair dilakukan dengan demo dan praktik. Tim memberikan penjelasan terlebih dahulu tentang perlengkapan dan bahan yang dibutuhkan serta penanganan masing-masing bahan. Adapun alat dan bahan yang diperlukan untuk membuat sabun piring cair dapat dilihat pada Tabel 1. 
Tabel 1. Alat dan Bahan Pembuatan Sabun Piring Cair

\begin{tabular}{ll}
\hline Alat yang Diperlukan & Bahan yang Diperlukan \\
\hline Ember 10 L & Texafon \\
Wadah 1 L & Sodium sulfat \\
Pengaduk & Glucotain \\
Gelas ukur & Metain \\
Timbangan & Litium alkil bisulfat \\
& Soda ash \\
& Pewangi \\
& Pewarna \\
& Air RO \\
\hline
\end{tabular}

Selanjutnya tim mendemokan cara membuat sabun piring cair dan para peserta mempraktikkannya secara berkelompok. Antusiasme IRT terlihat sampai akhir pelatihan seperti yang terlihat pada Gambar 2. Satu kendala yang ada saat pelatihan adalah peserta belum akrab dengan nama bahan dan belum bisa membedakan satu bahan dengan bahan lainnya. Akibatnya satu kelompok melakukan kesalahan saat mencampur bahan sehingga sabun yang dihasilkan kurang berbusa saat digunakan.
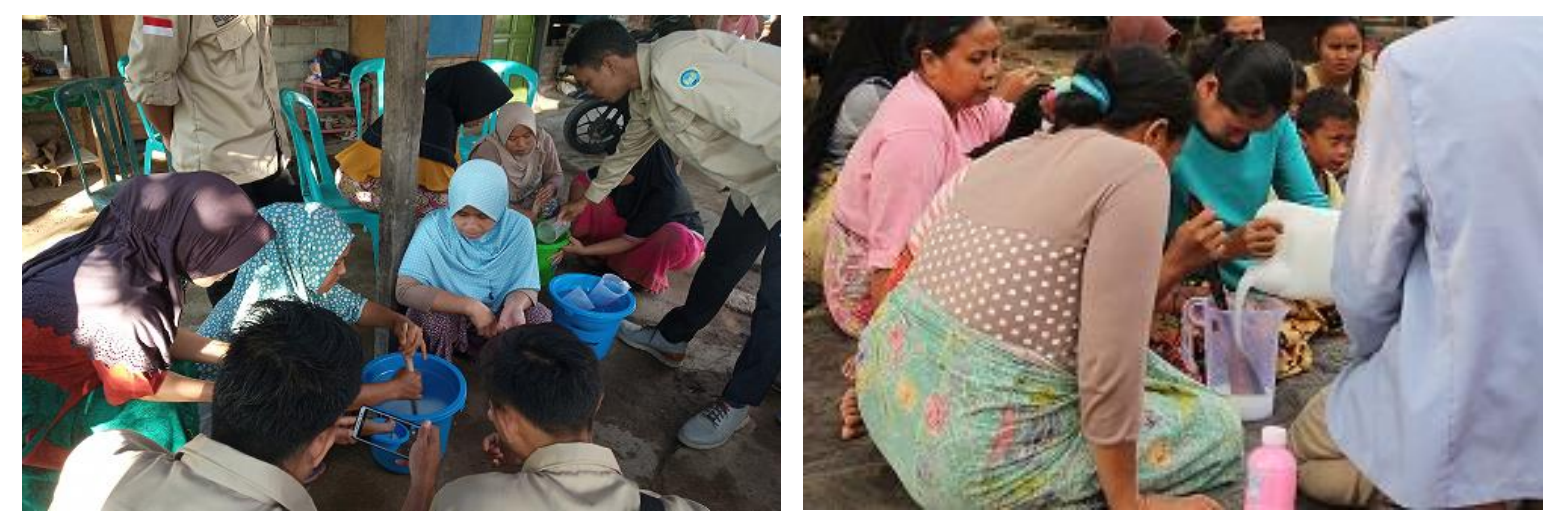

Gambar 2. Pelatihan Pembuatan Sabun Piring Cair

\section{Pendampingan}

Pada tahap ini, tim mengajak peserta untuk menganalisis modal pembuatan sabun piring cair dan menetapkan harga jual yang pantas. Setelah itu, IRT membuat dan mengemas produk sendiri dengan tetap didampingi oleh tim. Selanjutnya IRT menjual produk dengan menerapkan tips menaikkan penjualan yang telah dipelajari saat penyuluhan. Proses pendampingan dilakukan dengan tatap muka langsung dan melalui telepon. Secara keseluruhan ada sepuluh hari yang digunakan untuk memasarkan produk. Hasil penjualan tersebut dapat dilihat pada Gambar 3.

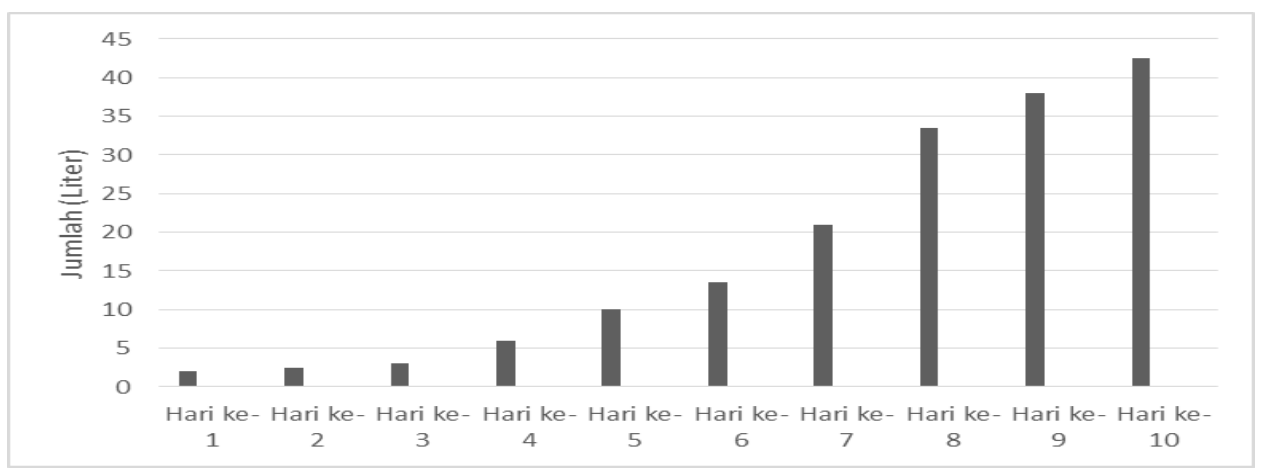

Gambar 3. Penjualan Sabun Piring Cair dalam Sepuluh Hari 
Penjualan sabun piring cair terus mengalami peningkatan karena peserta gencar melakukan promosi sehingga semakin banyak konsumen yang mengenal produk dan membelinya. Kewirausahaan sabun piring cair sudah menampakkan hasil yakni meningkatkan pendapatan IRT. Pelatihan seperti ini juga dapat membantu para ibu rumah tangga untuk menghemat pengeluaran keluarga (Haro, Waspodo, \& Handaru, 2017). Selain dapat dikomersilkan, sabun cuci piring yang diproduksi juga dapat dikonsumsi sendiri (Amalia et al., 2018).

\section{KESIMPULAN}

Pemberdayaan Ibu Rumah Tangga (IRT) di Desa Gondang telah berhasil dilaksanakan. Para IRT telah mendapatkan pengetahuan dan keterampilan dalam membuat sabun cair piring. Selain itu, IRT semakin termotivasi untuk berwirausaha melalui sabun piring cair. Antusias peserta terlihat dari awal sampai akhir kegiatan. Dalam waktu sepuluh hari, penjualan sabun piring cair sudah terlihat dapat meningkatkan pendapatan IRT.

\section{SARAN}

Tim pengabdian menyarankan agar para ibu rumah tangga tetap konsisten dalam menjalankan usaha sabun piring cair walaupun pelatihan telah berakhir. Di samping itu, para suami sebagai kepala rumah tangga diharapkan dapat memberikan dukungan terhadap kewirausahaan yang dijalankan oleh istrinya.

\section{UCAPAN TERIMA KASIH}

Tim pengabdian mengucapkan terimakasih kepada CV Chemika Karya yang telah mendukung penuh kegiatan ini.

\section{DAFTAR PUSTAKA}

Amalia, R., Paramita, V., Kusumayanti, H., Wahyuningsih, Sembiring, M., \& Rani, D. E. (2018). Produksi Sabun Cuci Piring Sebagai Upaya Peningkatkan Efektivitas Dan Peluang Wirausaha. Metana, 14(1):15-18.

Badan Pusat Statistik Kabupaten Lombok Utara. (2020). Kabupaten Lombok Utara dalam Angka Tahun 2020. Gangga: BPS Kabupaten Lombok Utara.

Christiana, Y., Pradhanawati, A., \& Hidayat, W. (2014). Pengaruh Kompetensi Wirausaha, Pembinaan Usaha dan Inovasi Produk Terhadap Perkembangan Usaha (Studi Pada Usaha Kecil dan Menengah Batik di Sentra Pesindon Kota Pekalongan). Diponegoro Journal of Social and Politic, 1-10. https://ejournal3.undip.ac.id/index.php/iiab/article/download/6601/6371)

Haru, A., Waspodo, A. A. W. S., \& Handaru, A. W. (2017). Peningkatan Keterampilan Bagi Ibu Rumah Tangga dalam Rangka Penghematan Melalui Pembuatan Sabun Cair Sederhana. Jurnal Pemberdayaan Masyarakat Madani (JPMM), 1(2), 194-206. DOI: 10.21009/JPMM.001.2.04

Lang, K., Massie, J., \& Ogi, I. (2015). Strategi Menciptakan Daya Saing Nilai Produk Usaha Mikro di Manado (Studi Kasus UD. Kloeman Bakery). Jurnal Berkala Ilmiah Efisiensi, 15(5), 646-655.

Latifa, N., Dewi, R., \& Fitriana. (2018). Peran Wirausaha dalam Meningkatkan Kesejahteraan Keluarga (Studi Kasus Usaha Penjahit Perempuan di Mukim Lhoknga). Jurnal Ilmiah Mahasiswa Pendidikan Kesejahteraan Keluarga, 3(2), 65-72.

Rahim, A. R., \& Basir, B. (2019). Peran Kewirausahaan dalam Membangun Ketahanan Ekonomi Bangsa. Economic Resources, 2(1), 34-39.

Suharyono. (2017). Sikap dan Perilku Wirausahawan. Jurnal Ilmu dan Budaya, 40(56), 65516586 
Telaumbanua, M., \& Nugraheni, M. (2018). Peran Ibu Rumah Tangga dalam Meningkatkan Kesejahteraan Keluarga. Sosio Informa, 4(2), 418-436.

Wahyudi, A., M., dan Septaryanto, J., (2020) Pelatihan Pembuatan Kelor Celup untuk Kesehaan Tubuh. Sasambo: Jurnal Abdimas (Journal of Community Service). 2(1), 1-6. Doi: $\underline{10.36312 / \text { sasambo.v1i2.127 }}$ 